\title{
Applying self-processing biases in education: improving learning through ownership
}

Sheila J. Cunningham

Lynda Scott

Jacqui Hutchinson

Josephine Ross

Douglas Martin

This is the accepted manuscript (C) 2018, Elsevier

Licensed under the Creative Commons AttributionNonCommercial-NoDerivatives 4.0 International (CC BY-NC-ND 4.0)

http://creativecommons.org/licenses/by-nc-nd/4.0/

$\left({ }^{(c)}\right)$ EY-No-ND

The published article is available from doi:

http://dx.doi.org/10.1016/j.jarmac.2018.04.004 
RUNNING HEAD: IMPROVING LEARNING THROUGH OWNERSHIP

\section{Applying self-processing biases in education:}

\section{Improving learning through ownership}

Sheila J. Cunningham ${ }^{1}$, Lynda Scott $^{1}$, Jacqui Hutchison ${ }^{1.2}$, Josephine Ross ${ }^{3}$ and Douglas

$$
\operatorname{Martin}^{2}
$$

1 Division of Psychology, Abertay University

2 School of Psychology, University of Aberdeen

3 Psychology, School of Social Sciences, University of Dundee

Address for correspondence:

Sheila Cunningham

Division of Psychology

School of Social and Health Sciences

Abertay University

Bell Street

Dundee

DD1 $1 \mathrm{HG}$

email: s.cunningham@abertay.ac.uk 


\title{
IMPROVING LEARNING THROUGH OWNERSHIP
}

\begin{abstract}
Accepting ownership of an item is an effective way of associating it with self, evoking self-processing biases that enhance memory. This memory advantage occurs even in ownership games, where items are arbitrarily divided between participants to temporarily 'own'. The current study tested the educational applications of ownership games across two experiments. In Experiment 1, 7 to 9-year-old children were asked to choose three novel, labelled shapes from an array of nine. The experimenter chose three shapes and three remained 'un-owned'. A subsequent free-recall test showed that children reliably learned more self-owned than otherowned or un-owned shapes. Experiment 2 replicated this finding for shapes that were assigned to owners rather than chosen, and showed that ownership enhanced memory more effectively than a control game with no ownership manipulation. Together, these experiments show that ownership games can evoke self-processing biases in children's memory, enhancing learning. Implications for education strategies are discussed.
\end{abstract}

Keywords: self, ownership, choice, learning, memory, education 


\section{IMPROVING LEARNING THROUGH OWNERSHIP}

Research suggests that linking items with the self reliably improves memory for these items (Rogers, Kuiper, \& Kirker, 1977; Symons \& Johnston, 1997). For example, one’s own possessions and experiences relating to oneself are better remembered than those associated with others. This 'self-reference effect' (SRE) on memory is a culmination of multiple selfprocessing biases, from facilitated perception and attention, to higher-order elaboration and organisation (Humphreys \& Sui, 2015; Klein \& Loftus, 1988). The prioritized processing of self-related information ensures that self-referencing is a robust and reliable memory enhancer, which could therefore be usefully applied in an educational context. The current inquiry investigates the efficacy of this approach through the development of a novel selfreferent learning task.

The potential value of self-referencing in educational contexts has been demonstrated by a small number of extant studies which show that modifying educational materials to include self-referent cues can be effective. These studies have included first-person pronouns or students' own names in materials, facilitating processing by evoking the attentional and mnemonic benefits of self-referencing (D’Ailly, Simpson \& MacKinnon, 1997; Moreno \& Mayer, 2000; Sinatra, Sims, \& Sottilare, 2014; Turk, Gillespie-Smith, McGowan, Havard, Conway, Krigolson, \& Cunningham, 2015). For example, Turk et al. (2015) tested 7- to 9year-old children's ability to accurately learn the spelling of novel (Experiment 1) and familiar (Experiment 2) words by practising the spellings in a self-referent or other-referent task. In the self-referent task, the children were asked to write sentences about themselves using the to-be-learned word, whereas the other-referent task required another character to be the subject of the sentence. Spelling test performance showed that the children benefitted from a significant learning boost in the self-referent condition, with mean scores up to $20 \%$ higher than in the other-referent condition. They also wrote significantly longer sentence during the practice, showing an increase in sustained attention to the task. This study provides 


\section{IMPROVING LEARNING THROUGH OWNERSHIP}

evidence that the SRE can be usefully applied in the classroom, supporting children's learning by increasing attention and memorial support.

Turk et al.'s study demonstrated that the self-referencing during the consolidation of new, to-be-remembered information can enhance children's memory. This manipulation shares features with the wider 'personalization' literature, in which it has been robustly demonstrated that modifying materials to match children's interests can be a highly effective strategy for increasing learning and engagement (see Cordova \& Lepper, 1996; Sadoski, Goetz, \& Rodriguez, 2000). Including a child's own name may be an extreme form of personalization, hence its effectiveness. However, problematically for educational practice, personalization paradigms as a whole are limited because incorporating specific names or interests is an intervention that cannot be applied to the majority of classroom learning tasks such as non-verbal items or group learning. They are also typically dependent on the ability of the individual to generate self-referent associations (e.g. producing a sentence involving self and to-be-remembered stimuli), and therefore may be constrained by age or ability. In the current study, we sought to test the efficacy of an alternative, more adaptable method of creating self-item associations: ownership. Although rich in terms of the encoding conditions generated, ownership is also one of the simplest ways to create an association between self and to-be-remembered information (Beggan, 1992; Belk, 1988). From as early as 2 years, children use possessive pronouns in spontaneous conversations with their peers (Hay, 2006), and can differentiate between objects on the basis of ownership, even when the item-person association is novel (Fasig, 2000).

The memorial effects of ownership were first demonstrated by Cunningham, Turk, MacDonald, and Macrae (2008), who asked pairs of participants to sort cards depicting shopping items into 'self-owned' and 'other-owned' baskets, on the basis of a color cue. A recognition memory test revealed a consistent advantage for items 'owned' by self, even 


\section{IMPROVING LEARNING THROUGH OWNERSHIP}

though this ownership was purely hypothetical, temporary and arbitrary. Importantly, this effect was not driven by acting on the objects (i.e., moving them into baskets) as action was independent of ownership and did not impact on item memory; rather the sense of personal relevance of the object at encoding seemed sufficient to enhance memory. Using this simple sorting paradigm, the ownership effect on memory has since been shown to emerge early in childhood (Cunningham, Vergunst, Brebner \& Turk, 2013; Ross, Anderson, \& Campbell, 2011) and be reliable across the lifespan (Hamani, Serbun, \& Gutchess, 2011).

There are a number of cognitive mechanisms that underlie the enhanced encoding of self-referent stimuli such as self-owned items, part of a functional system that ensures information of potential importance to self is not lost (Cunningham, 2016; Cunningham, Brady-Van den Bos, Gill, \& Turk, 2013; Humphreys \& Sui, 2016). One is the extensive and accessible self-knowledge framework, which enables elaborate and organised storage of selfreferent representations, relative to those linked to other people (Klein \& Kihlstrom, 1986; Klein \& Loftus, 1988; Symons \& Johnston, 1997). In addition, stimuli that are associated with self evoke cognitive biases that enhance encoding, particularly attention (Humphreys \& Sui, 2015). There is widespread evidence for attentional grab by self-referent stimuli such as one’s own name and face (Bargh, 1982; Brédart, Delchambre, \& Laureys, 2006; Cherry, 1953; Humphreys \& Sui, 2016; Tong \& Nakayama, 1999), and this pattern extends to owned objects (e.g., Gray, Ambady, Lowenthal, \& Deldin, 2004; Turk, van Bussel, Brebner, Toma, Krigolson, \& Handy, 2011; Turk, van Bussel, Waiter, \& Macrae, 2011). Demonstrating this effect, Turk, van Bussel, Brebner, et al. (2011) showed that ERPs associated with attentional focus differed when stimuli were cued as being self-owned vs. other-owned. Self-owned items were subject to both narrowed visuo-spatial attention indicated by a reduction in P1 response to peripheral stimuli, and increased executive attention shown by greater P300 response. The ownership effect on memory is therefore likely to arise as a result of multiple 


\section{IMPROVING LEARNING THROUGH OWNERSHIP}

processing biases, including both support by stored knowledge and increased attention, which maintain the reliability of the effect on memory and learning.

Interestingly, the level of self involvement with a stimulus can influence the magnitude of the SRE. Cunningham, Van den Bos and Turk (2011) adapted the ownership paradigm to allow participants to choose which items were to be assigned to self and which would be given to the other participant. In an initial experiment, they found that people were better at remembering self-chosen, self-owned items than they were at remembering selfowned items that were assigned to them by someone else. This was not due to any productspecific preference - a second and third experiment found that when participants believed that the objects were assigned on the basis of their own number choices, this 'illusion of choosing' (Cloutier \& Macrae, 2008) produced exactly the same pattern of memory performance: self involvement (choosing) exacerbated the ownership effect. This implies that choosing an item for self produces particularly strong ownership effects. The effect was not found when participants chose items for other people and was weakened when participants did not choose items for themselves. The strongest ownership effects may therefore be driven by the combination of self-reference and choice. Notably, these conditions offer the closest parallel to ownership in the real world, where we primarily chose items and actions for ourselves. Indeed, when making decisions for self, ownership might be considered a natural by-product of choice.

Agentive choice has for decades been considered a powerful social and education tool (see Katz \& Assor, 2007; Pattal, 2012 for review). Based on their finding that choice improved adults' performance on a paired associate learning task, Perlmutter and Monty (1977) argued that choice increased the perception of control, in turn increasing arousal, cognitive engagement and learning. Others have demonstrated that choice was not only cognitively motivating, but emotionally motivating, increasing feelings of self-efficacy and 


\section{IMPROVING LEARNING THROUGH OWNERSHIP}

competence in the learning context (e.g. Langer, 1975, Zuckerman, Porac, Lathin, Smith, \& Deci, 1978). This corresponds with Self-Determination Theory (Ryan \& Deci, 2000), which proposes that the satisfaction derived from agency, autonomy and control (inherent to making a choice) provides strong intrinsic motivation, resulting in persistence and engagement with the chosen activity. Importantly, these classic findings and theories translate into real world effects, with the introduction of choice in educational activity enhancing both enjoyment and learning in students (e.g. Cordova \& Lepper, 1996; Flowerday \& Schraw, 2000; Patall, Cooper, \& Robinson, 2008; Patall, Cooper, \& Wynn, 2010). For example, Cordova and Lepper (1996) found that choice over task-irrelevant aspects of a mathematical game (e.g., character names) significantly increased learning in children. It is therefore important to note that although ownership effects can be based solely on the attention grabbing or elaborative properties of the self-concept (as when the effect is observed in the absence of choice:

Cunningham et al., 2013; Ross et al., 2011), the strongest effects may derive support from the increased arousal and engagement that occurs when we perceive ourselves to be the agent of our own choices (Cunningham et al., 2011).

The current research develops a novel ownership task in order to establish whether children's learning can be improved through the association with self through ownership and choice (Experiment 1) or ownership alone (Experiment 2). Specifically, we asked 7- to 9year-old children to learn about novel labelled shapes by choosing (Experiment 1) and assigning (Experiment 2) the shapes to the ownership of the children themselves, or the experimenter. This paradigm differs from previous tests of the ownership effect because it is adapted to fit an educational context. Previous developmental tests of the effect (Cunningham et al., 2013; Ross et al., 2011) focused on establishing an age appropriate paradigm to observe the early emergence of self-reference effects, and so recruited largely preschool children ( 3 to 6 years). These children showed better memory for self-owned items, which 


\section{IMPROVING LEARNING THROUGH OWNERSHIP}

might be considered a marker of episodic learning. However, the information retained by the children referred to already familiar shopping items and concepts (yours/mine), rather than the retention of new information, key to early years education. As a result of these features, the extant literature lacks educational authenticity. The current study is the first to adapt the ownership paradigm specifically for educational application.

Across the two experiments, we predicted that the children would remember more of the self-owned shapes and their labels than those belonging to the experimenter, or those not owned by anyone. This is important, as it would imply that applying a very simple form of self-reference, which avoids relying heavily on words (contrasting Turk et al., 2015), might enhance the learning of novel information. Notably, ours is the first ownership study with children to include personal choice (Experiment 1). Although choice is not a necessary component of the ownership effect (see Cunningham et al 2011, Ross et al., 2013), it is typically implicated in real world ownership, exacerbates the ownership effect in adults (Cunningham et al., 2011), and has an established history in educational interventions (Katz \& Assor, 2007; Pattal, 2012). In Experiment 1, we expect to find a robust memory effect arising from the additive effects of self-reference and personal choice. In Experiment 2, we test for the first time whether ownership alone is sufficient to support learning in an educational context.

\section{Experiment 1: Learning of self- and other-chosen shapes}

The aim of Experiment 1 was to test the hypothesis that shapes encoded in the context of self-chosen ownership should be better remembered than shapes encoded in the context of ownership by others, or no ownership.

\section{Method}




\section{IMPROVING LEARNING THROUGH OWNERSHIP}

Participants and Design. Two primary schools classes of 7-9 year old children (approximately 30 children per class) were invited to participate in the study, from which 30 children returned written parental consent. The experiment therefore included 30 participants (16 female) aged 7-9 years (mean 7.11 years). The experiment had a repeated-measures design with all participants encoding novel shapes belonging to themselves and the experimenter, as well as un-owned shapes. It was approved by Abertay University's Research Ethics Committee.

Procedure. Children were tested individually by a single experimenter. The child and experimenter sat side by side at a table in a quiet area of the school. On the table were two large laminated 'shopping trolley' cards, both positioned in front of the child. There were also nine small square laminated cards presented face-up, each showing an outline of a novel shape (see Figure 1) associated with a novel single-syllable label (e.g., Bim, Dop, Mez). The to-be-remembered stimuli constitute the main difference between the current procedure and that of the original ownership paradigm adapted for children (Cunningham et al., 2013); the original paradigm tests memory for familiar items (e.g., toys), whereas this adaptation tests the encoding of novel information i.e. learning.

The children were told that they would play a game involving nine unusual shapes. Three would be owned by the child, three by the experimenter and three would be left on the table. The experimenter and child then took turns to select three shapes, with the person to pick first being counter-balanced across participants. When the experimenter selected a shape card, she placed it face up on 'her' trolley in front of the child. The child then selected a card and placed it on his/her own trolley. Once each trolley had three cards, the experimenter read aloud the names of the shapes that were hers, the child's and those that were left on the table (order counter-balanced across participants), reiterating the ownership (e.g., 'So your cards 


\section{IMPROVING LEARNING THROUGH OWNERSHIP}

are Dim, Lop and Mez [pointing]...". She noted the destination of all nine cards on a record sheet then put the cards into an envelope and out of sight. Previous studies have established that simply sorting objects in terms of 'possession' (yours/mine) is sufficient for self-object associations to be established (Cunningham et al., 2008), and is not problematic for young children (Cunningham et al., 2013; Ross et al., 2011).

After the brief delay created by the experimenter storing the stimuli, the child was given a blank sheet of paper and asked to draw as many of the novel shapes and write as many of the novel labels as s/he could remember. The child was given as long as they wanted to complete the task. When the child had not produced any drawing or writing for a 20 second period, the experimenter asked if s/he was finished. If the child said no, the waiting period was repeated. If the child said yes, the child was thanked and debriefed by the experimenter and returned to the classroom.

\section{Results}

The children's drawings were scored by two independent judges, blind to the nature of the experiment and to the shape ownership conditions. The child was awarded one point for every drawing that could be identified as being recognisable as one of the original nine shapes, and one point for each correctly remembered label (regardless of whether the corresponding shape was presented). Thus potential recall ranged from 0 to 18 shape stimuli (drawings or labels), split across the three ownership conditions. Each child's final score was the mean score from the two judges. Cohen's $\kappa$ showed a substantial level of agreement between the two judges, significantly above chance $(\kappa=.610$ (95\% CI 0.504 to 0.716$), p$ $<.001)$. Overall, children each recalled a mean of 2.6 shapes correctly (1.93 drawings and 0.67 labels). The children also produced unscored attempts, which were often close to the 


\section{IMPROVING LEARNING THROUGH OWNERSHIP}

original picture or label but not sufficiently matching to be scored as correct by the judges. These errors comprised $31.0 \%$ of total productions.

Proportionate recall scores were calculated by dividing the number of self-owned, other-owned, and un-owned stimuli correctly recalled by the number of items presented in each condition. Mean scores in each of the three conditions are shown in Figure 2.

\section{FIGURE 2 ABOUT HERE}

As Fig. 2 shows, the children tended to remember a higher proportion of self-owned stimuli $(M=0.26, S D=0.14)$ than other-owned $(M=0.11, S D=0.11)$ or un-owned stimuli $(M=0.07, S D=0.10)$. Univariate repeated measures ANOVA (Owner: self, other, neither) confirmed that the main effect of shape owner was significant $\left(F(2,58)=22.136, p<.001, \eta_{p}^{2}\right.$ $=.43$ ). Paired-samples t-tests confirmed that a higher proportion of self-owned stimuli were correctly recalled than either the other-owned $(t(29)=5.017, p<.001, d=0.927)$ or unowned stimuli $(t(29)=5.355, p<.001, d=1.332)$, while the tendency for other-owned stimuli to be remembered more than un-owned stimuli did not reach significance $(t(29)=1.535, p=$ $.136, d=0.282)$.

The children's choice was not equal across the available cards, with frequency of choice varying from 4 to 14 across the shapes $\left(\chi^{2}(8)=19.2, p<.001\right)$. This suggests that some cards were more desirable than others. However, there was no effect of choice order on subsequent memory - the card the child chose first (i.e., the most desirable from the full array) was not more likely to be remembered than the cards chosen from the subsequent, smaller arrays $\left(F(2,58)=1.462, p=.12, \eta_{p}^{2}=.048\right)$. 


\section{IMPROVING LEARNING THROUGH OWNERSHIP}

Additional analyses were run on the shape drawings and labels independently, revealing an identical pattern as the combined data. For drawings, self-owned stimuli were recalled more than both other-owned stimuli $(t(29)=3.33, p=.002, d=0.649)$ and neitherowned stimuli $(t(29)=4.52, p<.001, d=.994)$, which did not differ from one another $(t(29)$ $=1.43, p=.163, d=.265$ ). Similarly, for labels, self-owned stimuli were recalled more than both other-owned stimuli $(t(29)=3.28, p=.003, d=.634)$ and neither-owned stimuli $(t(29)$ $=3.34, p=.002, d=.660)$, which did not differ from one another $(t(29)=.465, p=.645, d=$. 0.086).

\section{Discussion}

Experiment 1 aimed to test the effectiveness of using an ownership game to improve memory for new to-be-learned information. The recollection scores showed that even within a small set of novel (therefore difficult), to-be-learned items, there was a reliable memory advantage for items that had been encoded as self-owned relative to other-owned or unowned items. Despite the simplicity of the manipulation and the small quantity of to-belearned items, ownership was an effective tool for increasing children's success on the difficult task of learning novel information presented only once.

It was found that self-ownership enhanced memory relative to both other-owned and un-owned shapes. This is consistent with previous research suggesting that participants show attentional and memorial biases for self-owned items (Cunningham et al., 2008; Turk, van Bussel, Brebner, et al., 2011), but shows for the first time the educational application of this effect. These results replicate and extend Turk et al.'s (2015) finding that the self-reference paradigm can be usefully adapted to the classroom to enhance the processing of novel information. Moreover, unlike Turk et al.'s (2015) self-reference paradigm and 


\section{IMPROVING LEARNING THROUGH OWNERSHIP}

personalization manipulations, the ownership paradigm does not rely heavily on individualization and can be applied flexibly, as shown here in the task's application to the learning of both verbal and visuospatial information that was not adapted to suit the interests of any individual child.

In Experiment 1, the children were asked to select the novel shapes they would own, potentially boosting the ownership effect by introducing the powerful memorial element of personal choice (see Cunningham et al., 2011; Katz \& Assor, 2007; Pattal, 2012). However, there may be drawbacks to the use of choice in an educational context. Firstly, stimuli that are perceived as attractive or meaningful to the child may be chosen for self, and supported in memory by other processing biases based on familiarity or positive emotion (e.g., Ashby, Isen, \& Turken, 1999; Epstein, Rock, \& Zuckerman, 1960; LeDoux, 1994). If the child is drawn to stimuli already imbued with memorable properties, the level of learning elicited by participants' sense of ownership is difficult to determine. Clarifying this issue is crucial from the perspective of establishing 'true' learning enhancement due to ownership. Secondly, although several researchers report a positive influence of choice on learning, the literature in this area is not unequivocal (e.g., Reeve, Nix \& Hamm, 2003). For example, Katz \& Assor (2007) note that providing choice is not always helpful in educational tasks where children do not feel competent, perhaps since they then perceive themselves to be the author of their own failure. Finally, there may often be practical pedagogical reasons to preclude choice, since it is often necessary for the teacher to identify the information that is to be remembered, rather than allowing children to drive the process. Giving the choice of ownership to the learning facilitator allows learning to be scaffolded within the zone of proximal development, rather than constrained by the child's independent choices. For these reasons, to assess whether ownership alone was sufficient to drive memory enhancement, a second experiment was conducted in which shapes were assigned to an owner rather than chosen. 


\section{IMPROVING LEARNING THROUGH OWNERSHIP}

As well as removing the element of choice from ownership, a further change for Experiment 2 was the inclusion of a control condition in which children sorted cards into different groups in the absence of an ownership instruction. In Experiment 1, a repeated measures design mitigated against the potentially sizeable individual differences that are likely to make group-level comparisons less reliable. However, this did not therefore allow a comparison with memory for items that were encoded in a non-ownership game. Previous research confirms that compared to non-game based learning, educational games (a.k.a. 'serious games'; Abt, 1970; Annetta, 2008) offer increased engagement, attention and memory support (e.g., see Connolly, Boyle, MacArthur, Hainey, \& Boyle, 2012; Miller, Chang, Wang, Beier, \& Klisch, 2011; Whitton \& Moseley, 2012). Therefore, it is important to test the effects of ownership against a control condition that is framed as a game. Further, it is critical to determine whether there is any 'cost' to the increased memorability of selfowned items in terms of reduced memory for items not owned by self, relative to baseline. In other words, it is possible that by increasing attention to self-owned items, ownership games could decrease learning of the items not owned by the child. This would have important implications for the use of ownership manipulations in a classroom. Experiment 2 was designed to test these issues.

\section{Experiment 2: Learning through assigned ownership}

The aim of Experiment 2 was twofold: first, in Experiment 1 there was a confound between personal choice and ownership, so we cannot be confident that ownership alone is sufficient to improve learning. The first purpose was therefore to test the hypothesis that ownership alone (without choice) can enhance memory in an educational context. Secondly, we included a control condition to provide a baseline measure of children's learning in this novel shape task, testing the hypothesis that memory in the ownership condition would be 


\section{IMPROVING LEARNING THROUGH OWNERSHIP}

higher than memory in the control condition. If the effect of ownership of memory is to be usefully applied in the classroom, then it needs to enhance learning relative to baseline, rather than other-owned or un-owned shapes suffering a 'cost' of reduced memory as a result of attention capture by the self-owned items (Turk et al., 2011).

\section{Method}

Participants and Design. Four classes of 7-9 year old children were asked to participate in the study, from which 84 children returned written parental consent. (The children were from different schools to those who participated in Experiment 1.) The final sample comprised 84 participants (40 female) aged 7-9 years (mean 7.96 years). The experiment had a mixed design, with participants from one school $(N=45,22$ female, mean age 7.74 years) completing the ownership condition, and participants from a second school in the same locality ( $N=39,18$ female, mean age 8.21 years) being assigned to the control condition. Classes from both schools were at the same stage and were not streamed by ability. The study was approved by Abertay University's Research Ethics Committee.

Procedure. Each child was tested individually by an experimenter at a table with three 'shopping trolley' cards and nine labelled shape cards. The children were told that they would play a game in which they had to sort nine novel shapes into the three colored trolley cards positioned in front of the child. Two between-subjects conditions were included: an ownership and a control condition.

In the ownership condition, three shapes were owned by the child, three by the experimenter and three were un-owned. The experimenter explained that ownership would be assigned on the basis of color matching - shapes with a red dot sticker under the label would 


\section{IMPROVING LEARNING THROUGH OWNERSHIP}

be assigned to ownership by the person who owned the red trolley, shapes with a yellow sticker would be assigned to ownership by the person who owned the yellow trolley, and shapes with no stickers would not be owned by anyone. Assignment of shapes to ownership condition and of color to owner was counterbalanced across participants, and the ownership of trolleys was explained to children when they were introduced to the sorting task. For this experiment, the child was always seated to the left of the experimenter, so although all trolleys were positioned in front of the child, they were arranged for clarity such that the child owned the trolley on the left, the experimenter owned the trolley on the right, and the unowned trolley was positioned in the centre.

In the control condition, no shape ownership was mentioned. Using the same colorstickered cards, the child was asked to place each card on the trolley that matched its sticker color. The three trolleys (red, green, and yellow) were positioned on the table, and their location in the left, centre and right position was counterbalanced across participants. The counterbalancing of shapes to color exactly matched the ownership condition, and all actions were matched except that children were sorting on the basis of color rather than owner.

After the instructions, the procedure across the ownership and control conditions was identical. The child was asked to put the cards face-up in the correct destination (i.e., one of the shopping trolleys in front of the child). The experimenter then verbalised the labels of the three categories of shapes (i.e., self-owned, other-owned, un-owned or red, yellow, green) in an order counter-balanced across participants. The cards were then put into an envelope and out of sight. As in Experiment 1, the child was then given a blank sheet of paper and asked to draw any shapes and write any labels that s/he could remember. S/he was given as long as required to complete the task. When the child had not produced any drawing or writing for a 20 second period, the experimenter asked if s/he was finished. If the child said no, the waiting 


\section{IMPROVING LEARNING THROUGH OWNERSHIP}

period was repeated. If the child said yes, the child was thanked and debriefed by the experimenter and returned to the classroom.

\section{Results}

The scoring procedure matched Experiment 1 exactly, with the same two judges who were blind to experimental condition. Again, Cohen's $\kappa$ showed a substantial agreement between the two judges, significantly above chance $(\kappa=.761$ (95\% CI 0.706 to 0.816$), p$ $<.001)$. Overall, children each recalled a mean of 2.7 shapes correctly (1.04 drawings and 1.70 labels), and produced many attempts that were not sufficiently accurate to be scored as correct (41.0\% of total productions). Mean scores are shown in Table 1 below.

\section{TABLE 1 ABOUT HERE}

The mean scores were submitted to a mixed 2 (Condition: Ownership, control) x 3 (Trolley: self-owned/left, other-owned/middle, un-owned/right). This confirmed a significant interaction between the two factors $\left(\mathrm{F}(2,164)=10.69, \mathrm{p}<.001 \eta_{p}{ }^{2}=.117\right)$, with the trolley having a very different effect in the ownership and control conditions.

In the Ownership condition, a univariate repeated measures ANOVA (Owner: self, other, neither) confirmed a significant effect of trolley (i.e., shape owner) $(F(2,88)=14.01, p$ $\left.<.001, \eta_{p}{ }^{2}=.24\right)$. Paired samples t-tests showed that all three comparisons produced significant differences (see Figure 3), with a higher proportion of self-owned stimuli being recalled $(M=0.29, S D=0.21)$ than either other-owned stimuli $(M=0.20, S D=0.18 ; t(44)$ $=2.11, p=.041, d=.338)$ or un-owned stimuli $(\mathrm{M}=0.07, \mathrm{SD}=0.15 ; t(44)=5.57, p<.001$, $d=.882$ ), and a higher proportion of other-owned stimuli being recalled than un-owned 


\section{IMPROVING LEARNING THROUGH OWNERSHIP}

stimuli $(t(44)=3.05, p=.004, d=.650)$. In contrast, there was no difference in stimulus recall between the three trolleys in the control (i.e., no ownership) condition $(F(2,76)=$ $\left.0.249, p=.780 \cdot \eta_{p}^{2}=.007\right)$.

\section{FIGURE 3 ABOUT HERE}

To assess the extent to which ownership impacted on memory in comparison to a baseline score, additional comparisons were tested between the proportionate mean recall across the three trolleys in the control condition, and recall in each of the three ownership conditions. An independent samples t-test showed that the difference between the control (mean .11, SD .07) and un-owned stimulus recall (mean .07, SD.15) did not reach significance $(t(82)=1.36, p=.179, d=.322)$. In contrast, there was a significant difference between recall in the control condition, and both the self-owned (mean .29, SD .21; $t(82)=$ $5.22, p<.001, d=1.305)$ and other-owned recall (mean $.20, \mathrm{SD} .19 ; t(82)=2.83, p=.006, d$ $=.698$ ), suggesting that there was no cost to the ownership effect in terms of other-item recall.

As in Experiment 1, the analysis was repeated for drawings and shapes separately and revealed a similar pattern to the combined data. In the Ownership condition, significantly more pictures were correctly reproduced for the self-owned stimuli than either the otherowned $(t(44)=2.08, p=.043, d=.342)$ or un-owned stimuli $(t(44)=3.65, p=.001, d=$ $.375)$, which did not differ significantly from each other $(t(44)=1.108, p=.274, d=.180)$. For the labels, the difference between self-owned and other-owned stimuli was in the predicted direction but did not reach significance $(t(44)=1.47, p=.149, d=.219)$, while the difference between self-owned and un-owned stimuli was significant $(t(44)=5.46, p<.001$, $d=.941)$. More other-owned than un-owned shape pictures were also produced $(t(44)=3.53$, 


\section{IMPROVING LEARNING THROUGH OWNERSHIP}

$p=.001, d=.764)$. In the Control condition, no paired comparison reached or approached significance.

\section{Discussion}

Experiment 2 replicated the ownership effect found in Experiment 1, showing that shapes encoded in the context of ownership by self are better remembered than either shapes owned by others or un-owned shapes. This effect remained robust even though the connection between the participant and the stimulus was theoretically weaker than in Experiment 1, taking the form of arbitrary, unchosen ownership. The fact that such a limited level of self-involvement with to-be-learned information can drive a robust memory effect suggests the ownership paradigm has considerable potential to be of use as a learning tool. Even when children were not given a choice of novel items to own, this minimal level of association with self was sufficient to produce an increase in retention of information. Unlike Experiment 1, this manipulation provides educators with complete control over the allocation of learning materials to owners. The finding that self-ownership improved learning of new information even without the inclusion of personal choice makes the paradigm particularly useful in a real-world educational context.

A second important finding was that the enhanced memory for self-owned items did not come at a cost to encoding of other information. Compared to a baseline control condition, self-owned and other-owned memory was increased, but there was no evidence for a reduction in memory for un-owned items (although it should be noted that the lack of random allocation of participants to ownership and control conditions is a limitation). This makes the ownership tool particularly valuable in the classroom, because it suggests that educators can use ownership manipulations to increase retention of materials without this 


\section{IMPROVING LEARNING THROUGH OWNERSHIP}

having a detrimental effect on memory for other encountered information. It should be noted that interpretation of results here is limited by the lack of random allocation of The pattern

suggests that the ownership effect in the current experiment did not occur because prioritized self-owned items were capturing attentional resources at the expense of other stimuli, as selfrelevant cues can do in experimental trials (e.g., Bargh, 1982; Harris, Pashler, \& Coburn, 2004; Röer, Bell \& Buchner, 2013). Rather, the results are consistent with Turk et al.'s (2015) suggestion that self-relevance can increase engagement to educational tasks, sustaining attention for longer than non self-relevant material.

Unlike Experiment 1, in this experiment un-owned items were significantly less likely to be remembered than those in the other two ownership conditions. Assigning ownership was valuable from a learning perspective even when the item was assigned to another person, being significantly higher than baseline control recall. One explanation for this is that unlike in a choice paradigm, in an assigned-ownership paradigm each item is potentially selfrelevant until the ownership assignment becomes clear so even other-owned items are initially attended to. Further, the children acted on all of the cards (unlike Experiment 1), perhaps increasing their attention to these cards relative to baseline. Although Cunningham et al. (2008) found no memory effect of acting on cards relative to another participant acting on the cards, that study did not include a control (no ownership) condition so may have underestimated the basic effect of item interaction on memory.

\section{General Discussion}

The current research establishes that children's ability to learn novel information is enhanced through association with self. Both experiments showed a reliable memory advantage for items 'owned' by self, rather than owned by another person or by no-one. This 


\section{IMPROVING LEARNING THROUGH OWNERSHIP}

is consistent with previous research suggesting that assigning ownership over stimuli creates a self-referent encoding bias, resulting in enhanced recollection (e.g., Cunningham et al., 2008, 2011, 2013; Ross et al., 2011; Van den Bos, Cunningham, Conway, \& Turk, 2010). The current demonstration that applying the ownership effect in an educational context offers a high-impact application is a valuable step forward for this line of research.

The findings are consistent with previous research showing that self-referential names and pronouns can improve performance on educational tasks (D’Ailly et al., 1997; Moreno \& Mayer, 2000; Turk et al., 2015). Indeed the findings strongly suggest that strategies which involve self-referencing should be utilised more widely as a learning tool. Unlike the previous methodologies, the value of the ownership paradigm is that it is adaptable; a multitude of diverse learning materials could be presented as ownership games. It would be relatively simple to incorporate to-be-learned information to be practised under the aegis of an ownership game on an individual, paired, or group basis. For example, it is easy to envisage children learning new spelling, foreign-language vocabulary, geographical facts, historical dates, or scientific terms in an ownership game to enhance retention of information. Given that the current findings suggest that when ownership of to-be-learned information is assigned, this increases memory for both self-owned and other-owned materials relative to baseline control, paired ownership learning games would be highly recommended. If teaching foreign language vocabulary, for instance, cards showing to-be-learned images and words could be created, and children asked to take turns choosing some to be their own cards (e.g., with a goal of creating the most colorful, valuable, or attractive set of pictures). Based on the current findings, we would expect children's learning of the images and vocabulary beloging to both themselves and their playing partner to be improved by this game. Multiple rounds could enhance learning even further by increasing the proportion of items encoded in a specific context of self-ownership. Importantly, since the ability to form ownership 


\section{IMPROVING LEARNING THROUGH OWNERSHIP}

associations emerges early (Fasig, 2000; Friedman \& Neary, 2008; Hay, 2006), the key manipulation should be accessible to children across age and ability levels, further enhancing the potential applications of ownership paradigms in an educational context.

Despite the usefulness of the current paradigm, there are a number of questions for educational practice that require further research. In particular, it would be important to determine the extent to which learned material was retained over time. Repeated testing after a delay of days or weeks would provide a valuable insight into the long-term retention of information encoded in the context of temporary ownership, which is of obvious importance in an educational context. Further, children in the current study were tested using surprise memory tests; they were not aware during encoding that they would benefit from rehearsal or other learning strategies. The potential for ownership to boost recall during active learning would be a valuable line of research.

An advantage of the ownership paradigm, from a psychological perspective, is that it is well understood at a theoretical level. Research using the standard ownership paradigm suggests that attention plays a driving role in the production of memory enhancement by ownership (Cunningham et al., 2013; Turk et al., 2011). As with other SREs, information linked to the self through ownership attracts attention (see Gray et al., 2004; Humphreys \& Sui, 2016; Turk et al., 2011; Turk, van Bussel, Waiter, \& Macrae, 2011), increasing the likelihood of subsequent recollection. In addition, information associated with the self is subject to enhanced perceptual processing (Sui, He, \& Humphreys, 2012; Sui, Rotschtein \& Humphreys, 2013) and facilitated verbal processing (Mood, 1979; Turk et al., 2015), both of which are likely to impact on the memory enhancement effect. Finally, any meaningful evaluation the child makes of the nonsense shape (e.g., 'that shape looks like the moon/an alien/a jug we have at home, I like it') can be stored in conjunction with rich, extant autobiographical memories which provide elaboration and organisation at encoding (Klein \& 


\section{IMPROVING LEARNING THROUGH OWNERSHIP}

Loftus, 1988; Symons \& Johnston, 1997). In sum, the multiple self-processing biases evoked when a stimulus is identified as relevant to self are activated by self-owned items, increasing the likelihood of their subsequent recollection.

In conclusion, the current study serves a proof-of-concept demonstration that ownership biases can enhance learning. The two experiments presented show that ownership can provide a significant learning advantage for material presented in an educational context. The paradigm can be manipulated so that the choice of to be learned material is selfvolitional or educator driven. The strength and reliability of the ownership effect suggests that this is a strategy that needs to be more widely disseminated, such that teachers can be made aware of this potentially valuable instrument in the educational toolbox.

\section{Author Contributions}

S. Cunningham designed the experiments, analyzed the data and wrote the manuscript. Lynda Scott and Sheila Cunningham collected data. J. Hutchison, D. Martin contributed to data processing and manuscript preparation. J. Ross provided theoretical input and contributed to the writing of the manuscript.

Acknowledgements

This project was supported by a Research Project Grant from the Leverhulme Trust (2014310) awarded to S. Cunningham and J. Ross. We thank Erin Taylor-Bennet for her help with Experiment 2 data collection. We also thank Andrew Butler and three anonymous reviewers for their very helpful comments on the manuscript. 


\section{References}

Abt, C. (1970). Serious games. New York: The Viking Press.

Annetta, L. A. (2008). Serious educational games: From theory to practice. Rotterdam: Sense Publishers.

Ashby, F. G., Isen, A. M., \& Turken, A. U. (1999). A neuropsychological theory of positive affect and its influence on cognition. Psychological Review, 106, 529-550. doi: 10.1037/0033-295X.106.3.529

Bargh, J. A. (1982). Attention and automaticity in the processing of self-relevant information. Journal of Personality and Social Psychology, 43, 425-436. doi:10.1037/00223514.43.3.425

Beggan, J. K. (1992). On the social nature of nonsocial perception: The mere ownership effect. Journal of Personality and Social Psychology, 62, 229-237.

Belk, R. W. (1988). Possessions and the extended self. Journal of Consumer Research, 15, 139-168. doi: 10.1080/17470210500343678

Brédart, S., Delchambre, M., \& Laureys, S. (2006). One's own face is hard to ignore. Quarterly Journal of Experimental Psychology, 59, 46-52. doi: $10.1080 / 17470210500343678$

Cherry, E. C. (1953). Some experiments on the recognition of speech, with one and two ears. Journal of the Acoustical Society of America, 25, 975-979. doi:10.1121/1.1907229

Cloutier, J., \& Macrae, C. N. (2008). The feeling of choosing: Self-involvement and the cognitive status of things past. Consciousness \& Cognition, 17, 125-135. doi: 10.1016/j.concog.2007.05.010 


\section{IMPROVING LEARNING THROUGH OWNERSHIP}

Connolly, T. M., Boyle, E. A., MacArthur, E., Hainey, T., \& Boyle, J. M. (2012). A systematic literature review of empirical evidence on computer games and serious games. Computers \& Education, 59, 661-686. doi:10.1016/j.compedu.2012.03.004

Cordova, D. L. \& Lepper, M. R. (1996). Intrinsic motivation and the process of learning: Beneficial effects of contextualization, personalization, and choice. Journal of Educational Psychology, 88, 715-730. doi: 10.1037//0022-0663.88.4.715

Cunningham, S. J. (2016). The function of the self-attention network. Cognitive Neuroscience, 7, 21-22. doi: 101080/ 17588928.2015.1075485

Cunningham, S. J., Brady-Van den Bos, M., Gill, L., \& Turk, D. J. (2013). Survival of the selfish: Contrasting self-referential encoding and survival processing. Consciousness and Cognition, 22, 237-244. doi: 10.1016/j.concog.2012.12.005

Cunningham, S. J., Turk, D. J., MacDonald, L. M., \& Macrae, C. N. (2008). Yours or mine? Ownership and memory. Consciousness and Cognition, 17, 312-318. doi: 10.1016/j.concog.2007.04.003

Cunningham, S. J., Vergunst, F., Macrae, C.N., \& Turk, D. J. (2013). Exploring early selfreferential memory effects through ownership. British Journal of Developmental Psychology, 31, 289-301. doi: 10.1111/bjdp.12005

Cunningham, S. J., Van den Bos, M., \& Turk, D. J. (2011). Exploring the effects of ownership and choice on self-memory biases. Memory, 19, 449-461. doi: $10.3758 / \mathrm{s} 13421-012-0279-0$

D’Ailly, H. H., Simpson, J., \& MacKinnon, G. E. (1997). Where should “you” go in a math compare problem? Journal of Educational Psychology, 89, 562-567. doi: $10.1037 / 0022-0663.89 .3 .562$ 


\section{IMPROVING LEARNING THROUGH OWNERSHIP}

Epstein, W., Rock, I., \& Zuckerman, C. B. (1960). Meaning and familiarity in associative learning. Psychological Monographs: General and Applied, 74, No. 491.

Fasig, L.G. (2000). Toddlers' understanding of ownership: Implications for self-concept development. Social Development, 9, 370-382. doi: 10.1111/1467-9507.00131

Flowerday, T., \& Schraw, G. (2000). Teachers' beliefs about instructional choice: A phenomenological study. Journal of Educational Psychology, 92, 634-645.

Flowerday, T., \& Schraw, G. (2003). Effect of choice on cognitive and affective engagement. Journal of Educational Research, 96, 207-215.

Friedman, O. \& Neary, K. R. (2008). Determining who owns what: Do children infer ownership from first possession? Cognition, 107, 829-849. doi: 10.1016/j.cognition.2007.12.002

Gray, H. M., Ambady, N., Lowenthal, W. T., \& Deldin (2004). P300 as an index of attention to self-relevant stimuli. Experimental Social Psychology, 40, 216-224. doi:10.1016/S0022-1031(03)00092-1

Hamami, A., Serbun, S. J., \& Gutchess, A. (2011). Self-referencing enhances memory specificity with age. Psychology and Aging, 26, 636-646. doi:10.1037/a0022626

Harris, C., Pashler, H., \& Coburn, N. (2004). Moray revisited: High-priority affective stimuli and visual search. Quarterly Journal of Experimental Psychology, 57A, 1-31. doi: $10.1080 / 02724890343000107$

Hay, D. (2006). Yours and mine: Toddlers' talk about possessions with familiar peers. British Journal of Developmental Psychology, 24, 39-52. doi: 1348/026151005X68880

Humphreys, G. W. \& Siu, J. (2016). Attentional control and the self: The self-attention network (SAN). Cognitive Neuroscience, doi: 10.1080/17588928.2015.1044427

Katz, I., \& Assor, A. (2007). When choice motivates and when it does not. Educational Psychology Review, 19, 429. doi: 10.1007/s10648-006-9027-y 


\section{IMPROVING LEARNING THROUGH OWNERSHIP}

Klein, S. B., \& Kihlstrom, J. F. (1986). Elaboration, organization, and the self-reference effect in memory. Journal of Experimental Psychology: General, 115, 26-38. doi:10.1037/0096-3445.115.1.26

Klein, S. B., \& Loftus, E. M. (1988). The nature of self-referent encoding: The contribution of elaborative and organizational processes. Journal of Personality and Social Psychology, 55, 5-11. doi:10.1037/0022-3514.55.1.5

Langer, E. J. (1975). The illusion of control. Journal of Personality and Social Psychology, 32, 311-328. doi: 10.1037/0022-3514.32.2.311

LeDoux, J. (1994). Emotion, memory and the brain. Scientific American, 270, 50-57. doi: 10.1038/scientificamerican0694-50

Miller, L. M., Chang, C.-I., Wang, S., Beier, M. E., \& Klisch, Y. (2011). Learning and motivational impacts of a multimedia science game. Computers \& Education, 57, 1425-1433. 10.1016/j.compedu.2011.01.016

Mood, D. M., (1979) Sentence comprehension in preschool children: Testing an adaptive egocentrism hypothesis. Child Development, 50, 247-250.

Moreno, R. \& Mayer, R. E. (2000). Engaging students in active learning: The case for personalized multimedia messages. Journal of Educational Psychology, 92, 724-733. doi: $10.1037 / 0022-0663.92 .4 .724$

Patall, E. A., Cooper, H., \& Robinson, J. C. (2008). The effects of choice on intrinsic motivation and related outcomes: A meta-analysis of research findings. Psychological Bulletin, 134, 270-300. doi: 10.1037/0033-2909.134.2.270

Patall, E. A., Cooper, H., \& Wynn, S. R. (2010). The effectiveness and relative importance of choice in the classroom. Journal of Educational Psychology, 102, 896-915. doi: $10.1037 / \mathrm{a} 0019545$ 


\section{IMPROVING LEARNING THROUGH OWNERSHIP}

Reeve, J., Nix, G., \& Hamm, D. (2003). Testing models of the experience of selfdetermination in intrinsic motivation and the conundrum of choice. Journal of Educational Psychology, 95, 375-392. doi: 10.1037/0022-0663.95.2.375

Röer, J. P., Bell, R., \& Buchner, A. (2013). Self-relevance increases the irrelevant sound effect: Attentional disruption by one's own name, Journal of Cognitive Psychology, 25, 925-931. doi: 10.1080/20445911.2013.828063

Rogers, T. B., Kuiper, N. A., \& Kirker, W. S. (1977). Self-reference and the encoding of personal information. Journal of Personality and Social Psychology, 35, 677-688. doi:10.1037/0022-3514.35.9.677

Ross, J., Anderson, J. R., \& Campbell, R. N. (2011). I remember me: Mnemonic selfreference effects in preschool children. Monographs of the Society for Research in Child Development, 76, 1-102. doi:10.1111/j.1540-5834.2011.00613.x

Ryan, R. M., \& Deci, E. L. (2000). Self-determination theory and the facilitation of intrinsic motivation, social development, and well-being. American Psychologist, 55, 68-78. doi: 10.1037/0003-066X.55.1.68

Sadoski, M., Goetz, E. T., \& Rodriguez, M. (2000). Engaging texts: effects of concreteness on comprehensibility, interest, and recall in four text types. Journal of Educational Psychology, 92, 85-95. doi: 10.1037/0022-0663.92.1.85

Sinatra, A. M., Sims, V. K., \& Sottilare, R. A. (2014). The need for cognition and selfreference on tutoring a deductive reasoning skill. Technical Report (No. ARL-TR6961), Army Research Laboratory.

Sui, J., He, X., \& Humphreys, G. W. (2012). Perceptual effects of social salience: evidence from self-prioritization effects on perceptual matching. Journal of Experimental Psychology: Human Perception and Performance, 38, 1105-1117. doi:10.1037/a0029792 


\section{IMPROVING LEARNING THROUGH OWNERSHIP}

Sui, J., Rotshtein, P., \& Humphreys, G. W. (2013). Coupling social attention to the self forms a network for personal significance. Proceedings of the National Academy of Sciences, 110, 7607-7612. doi: 10.1073/pnas.1221862110

Symons, C. S., \& Johnson, B. T. (1997). The self-reference effect in memory: A metaanalysis. Psychological Bulletin, 121, 371-394. doi:10.1037/0033-2909.121.3.371

Tong, F., \&; Nakayama, K. (1999). Robust representations for faces: Evidence from visual search. Journal of Experimental Psychology: Human Perception and Performance, 25, 1016-1035. http://dx.doi.org/10.1037/0096-1523.25.4.1016

Turk, D. J., Gillespie-Smith, K., McGowan, L., Havard, C., Conway, M. A., Krigolson, \& Cunningham, S. J. (2015). Selfish learning: The impact of self-referential encoding on children's literacy attainment. Learning \& Instruction, 40, 54-60. doi: 10.1016/j.learninstruc.2015.08.001

Turk, D. J., van Bussel, K., Brebner, J. L., Toma, A., Krigolson, O., \& Handy, T. C. (2011). When IT becomes MINE: Attentional biases triggered by object ownership. Journal of Cognitive Neuroscience, 12, 3725-3733.doi:10.1162/jocn_a_00101

Turk, D. J., van Bussel, K., Waiter, G. D., \& Macrae, C. N. (2011). Mine and me: Exploring the neural basis of object ownership. Journal of Cognitive Neuroscience, 11, 36573668. doi:10.1162/jocn_a_00042

Van den Bos, M., Cunningham, S. J., \& Turk, D. J. (2010). Mine to remember: The effects of minimal ownership on remembering and knowing. Quarterly Journal of Experimental Psychology, 63, 1065-1071. doi:10.1080/17470211003770938

Whitton, N \& Moseley, A. (2012). Using games to enhance learning and teaching: A beginner's guide. New York: Routledge. 


\section{IMPROVING LEARNING THROUGH OWNERSHIP}

Zuckerman, M., Porac, J., Lathin, D., Smith, R., \& Deci, E. L. (1978). On the importance of self-determination for intrinsically motivated behavior. Personality and Social Psychology Bulletin, 4, 443-446. doi: 10.1177/014616727800400317 


\section{IMPROVING LEARNING THROUGH OWNERSHIP}

Table 1

Mean recall of stimuli (raw scores) in the Ownership and Control conditions

\begin{tabular}{|c|c|c|c|}
\cline { 2 - 4 } \multicolumn{1}{c|}{} & \multicolumn{3}{c|}{ Mean (SD) stimuli recalled } \\
\hline \multirow{3}{*}{ Ownership condition } & Self-owned & Other-owned & Un-owned \\
\cline { 2 - 4 } & $1.74(1.23)$ & $1.2(1.13)$ & $0.44(0.90)$ \\
\hline \multirow{3}{*}{ Control condition } & Left trolley & Middle trolley & Right trolley \\
\cline { 2 - 4 } & & & $0.71(0.78)$ \\
\hline
\end{tabular}




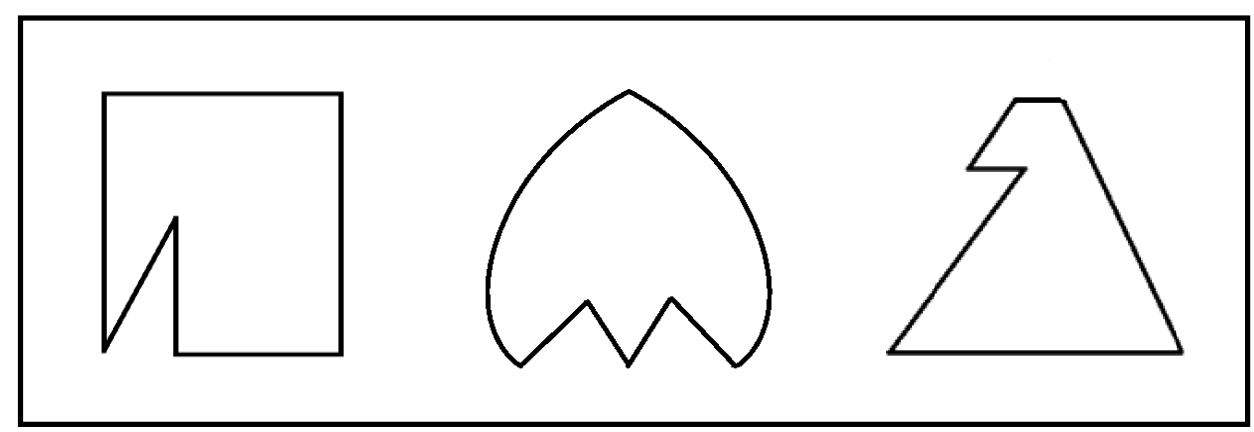

Figure 1: Example shape images used in the encoding task 


\section{IMPROVING LEARNING THROUGH OWNERSHIP}

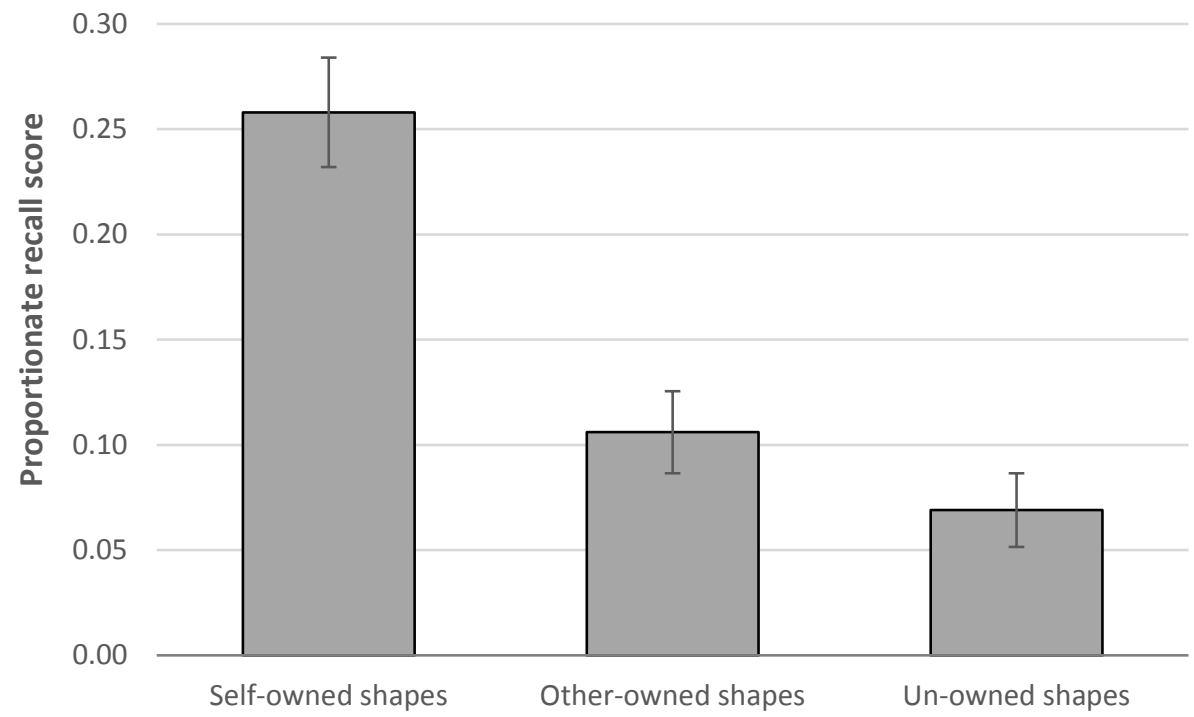

Figure 2: Mean proportionate recall scores for self-owned, other-owned and un-owned stimuli in Experiment 1 (error bars represent one standard error of the mean). 


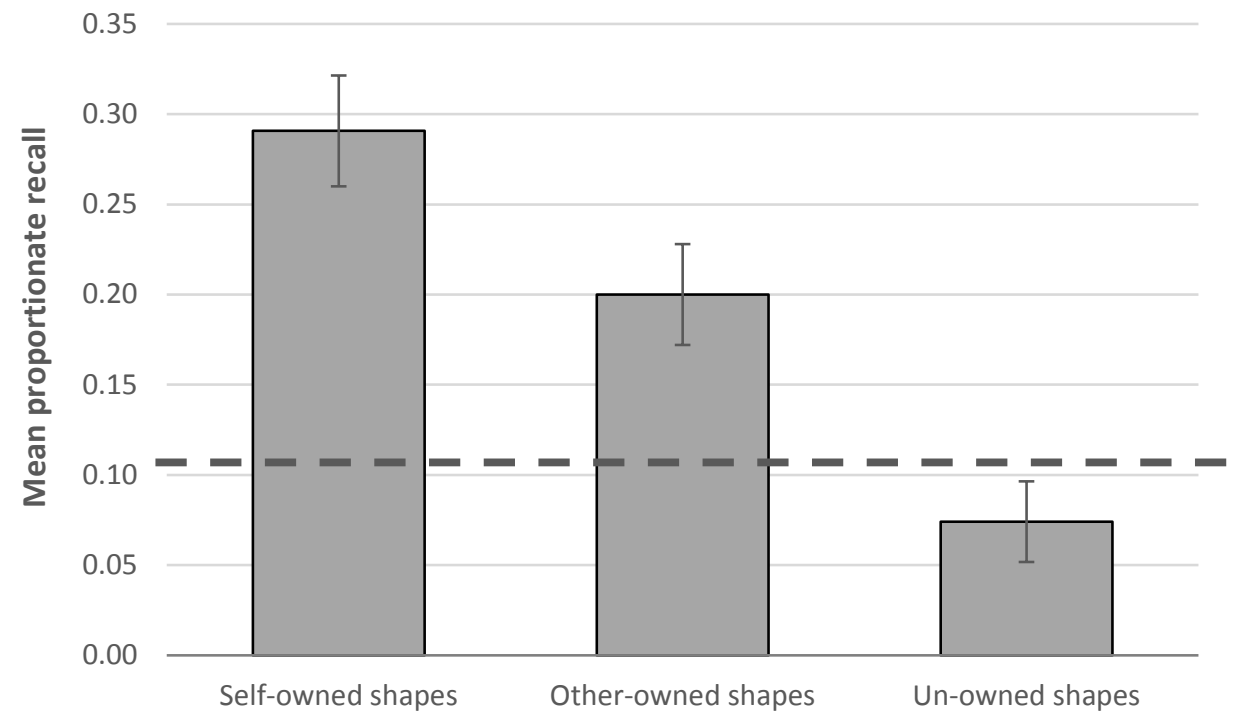

Figure 3: Mean proportionate recall scores for self-owned, other-owned and un-owned stimuli in the Ownership condition in Experiment 2 (error bars represent one standard error of the mean). The dotted line represents mean recall in the Control condition. 